\title{
Pilates as an effective means for developing physical qualities of Agricultural University students
}

\author{
Olga Druzhinina, Natalya Vershinina, Lada Mart'yanova, Roman Zhujkov, Oleg Kosenovich \\ Izhevsk State Agricultural Academy, 426069, Izhevsk, Russia
}

\begin{abstract}
The Pilates method was developed about 100 years ago. It is popular among students. This method combines low-impact, health-improving and muscle-strengthening exercises for backbone and muscles strengthening. It may be said that Pilates provides complex load for all muscle groups. In physical education classes at Agricultural University, aerobics and Pilates means are wildly used. In this article, the results of the experimental method, based on the usage of Pilates means among Agricultural University students, are given. The students doing aerobics were divided into 2 groups (control group and experimental group). During the academic year, the students of the experimental group were doing Pilates. The lecturers of Physical Education Department at Izhevsk State Agricultural Academy were monitoring state of health and physical conditions of the students. Finally, positive results were received. The effectiveness of the experimental Pilates method was proven, as physical and mental conditions of the students were improved. And some of the health indicators were increased.
\end{abstract}

\section{Introduction}

It is known that one of the main purposes of physical education at university - establishing the competences for using physical education means for health promotion, strengthening of psychomotor skills, physical and mental capacities, and keeping them at optimal level. During the studies, it is necessary to develop and improve physical qualities. Some authors defined professionally important qualities for students that are developed in physical education (PE) classes [1]. Moreover, it is also necessary to consider interactive technologies during PE classes. They help to increase students' motivation to study [2]. So it is essential to choose physical culture means contributing to effective physical training of students. One of such means is Pilates.

Pilates, as form of fitness, is good for functional state, physical training, and work capacity of students. Pilates exercises are focused on increasing strength endurance, improving flexibility and joint mobility, and usage of special breathing technique enables to increase functional training level. Pilates exercises are aimed at increasing strength and flexibility, the importance of which cannot be overstated for health.

Recent studies proved experimentally that exercises performed according to Joseph Pilates's method have positive effect on psychophysical and psychoemotional states $[3,4,5,6]$.

People doing Pilates get new opportunities. They help to improve functional state of body, to increase the level of physical work capacity. Pilates exercises are of great importance for prevention of backbone diseases, correction of postural disorders. They are focused on correction and prevention of musculoskeletal diseases, and also on strengthening of the main muscle groups. Pilates is an ideal health-improving means for obese people, for people that suffer from vegetovascular dystonia, varicosity, osteochondrosis, and reduced work capacity [6].

Though, Pilates is rather popular among some specialists of physical education $[3,4,6]$, we suppose that the question concerning Pilates as an effective means for developing physical qualities in PE classes has not been studied enough.

\section{Materials and methods}

In order to investigate the influence of Pilates on body and development of students' physical qualities, we have studied the principles of Pilates.

A number of exercises and methods of Pilates are based on fixed principles by following which during training students will be able to recover muscular and psychoemotional balance. They are: relaxation, concentration, coordination, alignment, and breathing.

Relaxation refers to the ability to work without excessive stress. While relaxing the body before each exercise and focusing on target body area, a person learns how to position the body correctly and how to maintain this position without excessive stress. This particular skill will help to prevent injuries during physical training. However, relaxation should be combined with concentration. 
Concentration refers to the ability to direct thoughts on a particular part of the body that is currently being worked at. This is a real achievement. It will take time to learn to do this but it will be paid off in the future. Some of Pilates exercises require mental determination, but as the training course proceeds, these movements will be done unconsciously. While doing the exercises correctly, students "help" their central nervous system to choose the right muscle combination for the target movement. It becomes possible to reprogram the body towards using different muscles.

Coordination is associated with the ability of focusing attention and closely related to the ability of coordinating one's movements. In classes students should perfectly learn how to become awareness of every movement. Gradually, movements are becoming more refined and smooth. Coordination is essential not only during the training, but in everyday life of young people.

While doing Pilates exercises, a person should align the main body axes. It implies the principal of alignment. While doing this, the backbone should be stretched along its full length. It will allow increasing the distance between vertebral discs, thereby developing flexibility and body mobility. When students get used to align their body during exercises, they form correct posture. Internal organs gradually take their initial places. Such internal organs positions will be stabilized by regular training that support their muscles.

It is necessary to breathe deeply, while inhaling ribs should move apart. Here, it is essential not to change to abdominal type of breathing. Shoulders should be kept down in order to open the chest. When breathing correctly, one can notice that the brain functions and state of health are improving as a result of more intensive oxygen exchange [4].

The exercises are focused on the development of muscle strength, especially on strengthening abdominal and back muscles, improving flexibility and mobility in backbone, and also on improving physical and mental states, namely, good blood circulation, deep breathing and increased lung capacity, healthy bones, strong abs, increased tonus and reduced stress levels [5].

Pilates popularity is increasing all over the world, and modern students also show interest for this type of exercises.

Therefore, the lectures at Izhevsk State Agricultural Academy use Pilates exercises not only during PE classes for students of special medical group and students who are withdrawn from active physical activity (running, jumping, etc.), but also in aerobics classes for students of the main medical group. The advantage of this method is that students with different training levels get complex effects on all muscle groups.

Pilates is a compound system that influences people's state of mind, their intelligence, intellect, and at the same time it develops strength, flexibility, endurance, and motion coordination.

During the classes, not only large superficial muscles work, but also small deep muscles that require particular approach and specific training. Special attention is paid to core strength, the state of which is directly connected to overall body development. Pilates is coupled well with any cardiovascular exercises and weight training where gym machines are used [7].

While studying the topic of Pilates, we have used the following research methods: analysis and compilation of literature sources, survey, and testing, educational experiment, mathematical and statistical analysis of the data received.

\section{Results and discussion}

After having studied the literature sources, we have understood how to develop Pilates exercises in aerobics classes in theory. But it remained unknown how to use them in practical classes. Therefore, we asked students to answer the following question: "How do you regard Pilates classes?" The received answers are described below.

The survey was conducted among 1,2 and 3-year students of Izhevsk State Agricultural Academy in "Aerobics" specialty; the total number of students was 500. The answers to the question: "Why do you like PE classes, and particularly Pilates classes?" were as follows.

Possibility of health improving - 65\%, communicating with friends $-5 \%$; increasing of fitness level - 70\%; possibility of taking a rest from studies that require mental efforts $-15 \%$; posture improvement $-24 \%$; body improvement $-34 \%$; enhancing of authority among people $-5 \%$; improvement of physical fitness (increasing the level of physical qualities, physical work capacity) - 85\%; getting new knowledge about human performance, and types of fitness $-56 \%$.

The answers to the question: "How did Pilates classes affect your state of health?" were as follows. Very well $87 \%$, well - $10 \%$; satisfactorily - $3 \%$.

As part of the study, the educational experiment was carried out. Group of students in "Aerobics" specialty were divided into EG (experimental group) (30 students) and CG (control group) (30 students). For students of CG the traditional working program on aerobics according to Federal Educational Standard (FES) 3++ was used. For students of EG the experimental Pilates method was applied. The principle of the method implies giving Pilates exercises during PE classes. The main part of the training class included sets of exercises of different complexity [8]. Figure 1 shows a typical set of Pilates exercises. 
1

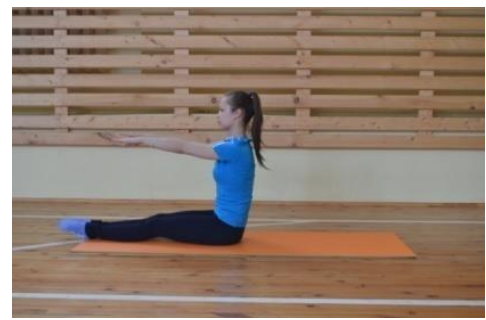

4

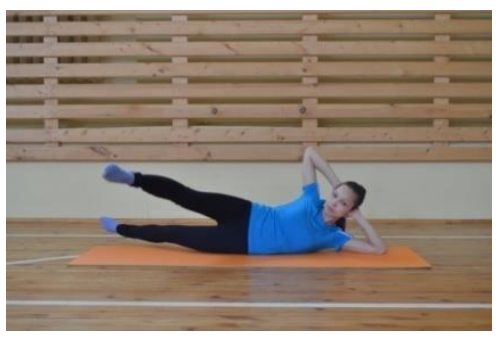

7

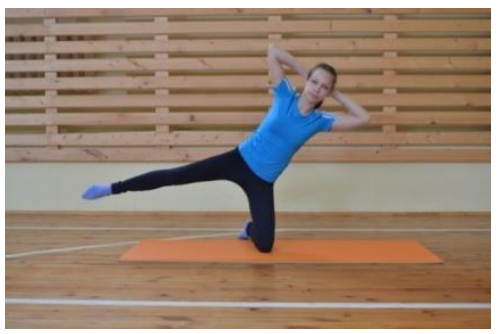

10

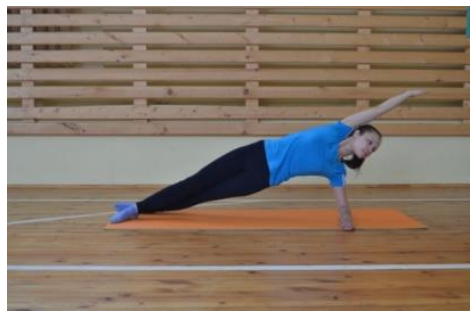

2

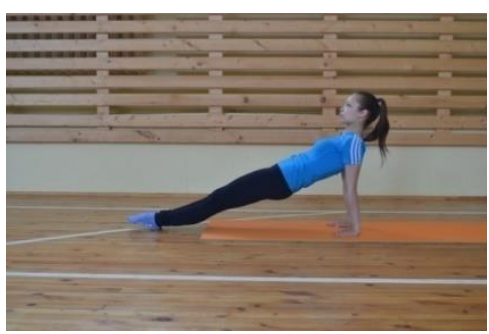

5

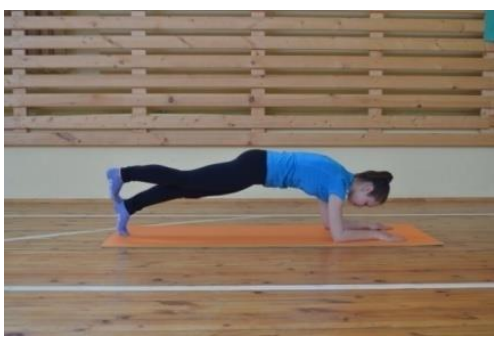

8

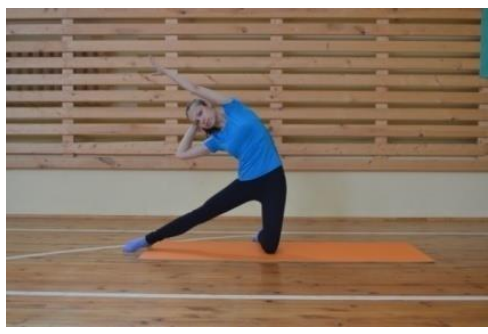

11

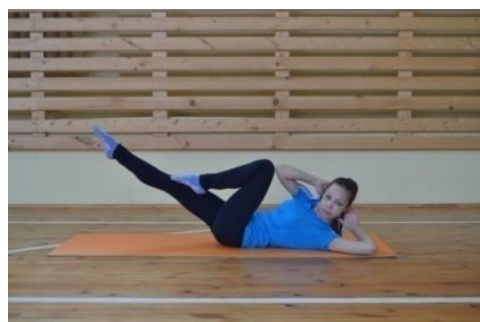

3

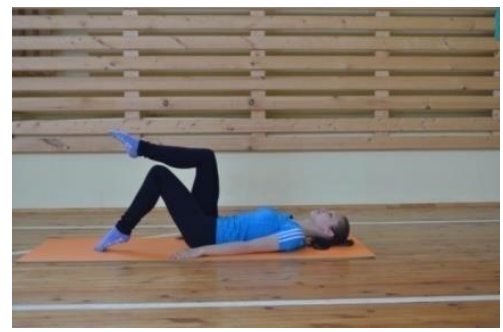

6

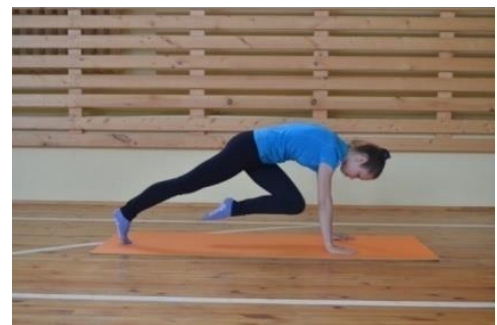

9

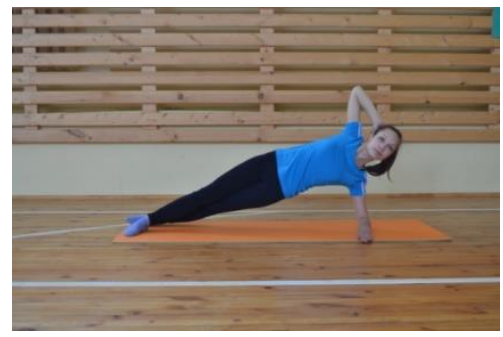

12

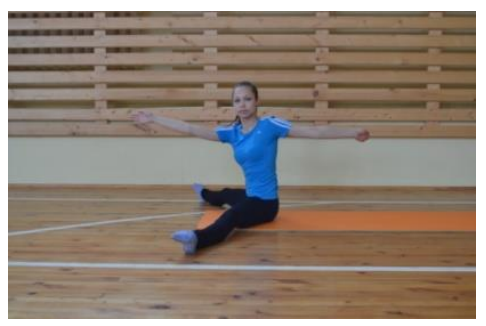

Fig. 1. Typical set of Pilates exercises for EG students

Exercises 1-12 in Figure 1 strengthen all muscle groups. Exercises should be done in a stepwise manner, starting from 8 times.

Also, sets of circuit training were applied to EG students [8]. Figure 2 shows a typical set.

Circuit training is based on aforementioned Pilates principles. The set consists of 6 exercises for different muscle groups. The exercises should be done in a stepwise manner, starting from 8 times with 3 circuits.

Exercise 1
Exercise 2
Exercise 3 


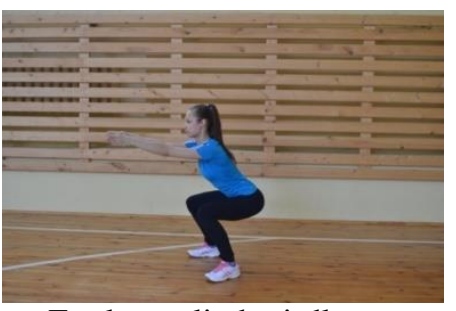

For lower limb girdle muscles

Exercise 4

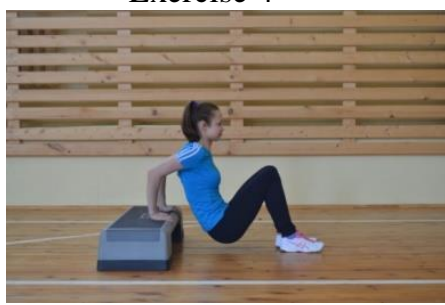

For shoulder girdle muscles

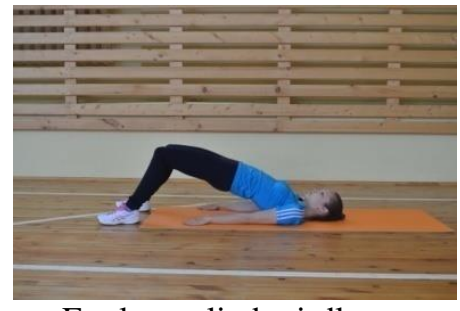

For lower limb girdle muscles

Exercise 5

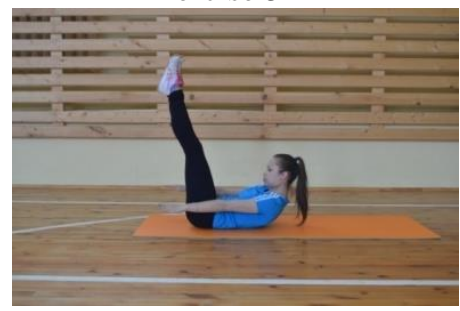

For abdominal muscles

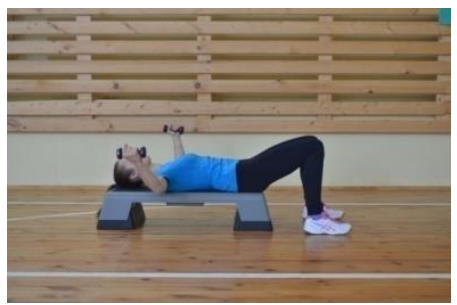

For shoulder girdle muscles

Exercise 6

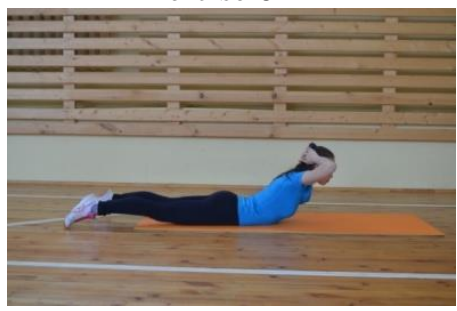

For back muscles

Fig. 2. Typical set of circuit training for EG students.

In order to identify physical training indicators change and etc., the students were tested before and after the experiment. Indicators of physical state, mental condition of people under test, by using Landolt ring test, and physical fitness indicators (turning up and lowering the body while lying on the back, pushing-up, toe touch bending while standing on a bench) were studied.

As a result, EG students experienced the following positive changes that are given below.

According to the research data, students of both groups had almost equal initial and final average values of body weight, namely, in control group (50 and 51), and in experimental group (53 and 53.5). It can be explained by low amount and intensity of training load, and therefore insignificant change of body weight.

Body length of EG students did not change during the experiment, and was about $160 \mathrm{~cm}$.

By using the index method, we wanted to define body peculiarities after doing Pilates exercises. For this purpose, body mass index (body weight - length relationship) was calculated.

Body mass index was calculated from the following equation:

Body mass index $=$ weight $(\mathrm{g}) /$ height $(\mathrm{cm})$.

Average value: 370-400 g per $1 \mathrm{~cm}$ of men's height, 325-375 g per $1 \mathrm{~cm}$ of women's height (see Table 1).

Table 1. Body mass index for students aged 19-25

\begin{tabular}{|c|c|c|c|}
\hline \multicolumn{2}{|c|}{$\begin{array}{c}\text { Age } \\
\text { (years) }\end{array}$} & \multicolumn{2}{c|}{ Constitutional type } \\
\hline \multicolumn{2}{|c|}{ asthenic } & normosthenic & hypersthenic \\
\hline $19-25$ & 325 & 345 & 370 \\
\hline
\end{tabular}

Our research has shown insignificant change of the results for both groups: control group (333 and 335); experimental group (328 and 330), due to the fact that main and deep muscle groups were worked out equally, and consequently less fat deposits in abdominal muscles, thighs, and hands. These results can be explained by the training scheme -health improving classes, and low amount and intensity of training load.

The most important aspects of J. Pilates's method were chest and breathing. Therefore, it is rather interesting to check how lung capacity ratio changes after the experiment. Lung capacity ratio characterizes primarily strength of respiratory muscles and lung tissue elasticity. It varies to a great extent. It depends on a variety of causes: height, age, sex, weight, chest size, duration of PE classes.

Our research data has shown certain changes of this indicator in Pilates classes. The results received are explained by the fact that Pilates exercises actively use different breathing techniques. Breathing control is performed based on three main aspects. They are called "lateral breathing", "rhythmic pattern observation", and "active breathing", all these have a positive effect on respiratory muscles training.

Pilates helps to keep psychoemotional balance, thereby it is important for concentration and stability of attention. We measured these indicators by using Landolt ring test with a table. This method defines the information processing rate, efficiency, endurance ratio, precision factor, development level of attention concentration, etc.

Table 2 shows the results for particular indicators of Landolt ring test.

Table 2. Landolt ring test results

\begin{tabular}{|l|l|l|l|l|} 
Indicator & Group & Before the & After the experiment & Increase in $\%$ \\
\hline
\end{tabular}




\begin{tabular}{|c|c|c|c|c|}
\hline & & experiment & & $33 \%$ \\
\hline \multirow{2}{*}{ Endurance ratio } & \multirow{2}{*}{ CG } & $15 \%$ & $10 \%$ & $66 \%$ \\
\cline { 2 - 5 } & EG & $15 \%$ & $5 \%$ & $20 \%$ \\
\hline \multirow{2}{*}{ Precision factor } & $\mathrm{CG}$ & $15 \%$ & $12 \%$ & $41 \%$ \\
& $\mathrm{EG}$ & $17 \%$ & $10 \%$ & $23 \%$ \\
\cline { 2 - 5 } & $\mathrm{CG}$ & $57 \%$ & $70 \%$ & $37 \%$ \\
\hline $\begin{array}{c}\text { Development level of } \\
\text { attention concentration }\end{array}$ & $\mathrm{EG}$ & $68 \%$ & $93 \%$ & \\
\cline { 2 - 5 }
\end{tabular}

As one can see from Table 2, increase of indicators in EG students is higher compared to CG students. This fact indicates the efficiency of this experimental method in keeping of students psychoemotional balance during Pilates classes.

Also, physical fitness dynamics of students was observed, the results are given in Table 3.

Table 3. Physical fitness of CG and EG students of Izhevsk State Agricultural Academy

\begin{tabular}{|c|c|c|c|}
\hline Indicator & Group & $\begin{array}{c}\text { Before the } \\
\text { experiment }\end{array}$ & After the experiment \\
\hline $\begin{array}{c}\text { Turning up and lowering the body } \\
\text { while lying on the back (number of } \\
\text { times) }\end{array}$ & CG & $35 \pm 0.1$ & $38 \pm 0.4$ \\
\cline { 2 - 4 } & EG & $36 \pm 0.2$ & $45 \pm 0.5$ \\
\hline Pushing-up (number of times) & CG & $10 \pm 0.7$ & $12 \pm 0.4$ \\
\cline { 2 - 4 } & EG & $11 \pm 0.6$ & $17 \pm 0.6$ \\
\hline $\begin{array}{c}\text { Toe touch bending while standing on a } \\
\text { bench (cm) }\end{array}$ & CG & $6 \pm 0.1$ & $8 \pm 0.2$ \\
\cline { 2 - 4 } & EG & $7 \pm 0.6$ & $12 \pm 0.7$ \\
\hline
\end{tabular}

It can be seen from Table 3, that EG students had better results with respect to physical fitness standard, compared to KG students.

\section{Conclusions}

The research carried out by the lectures of Izhevsk State Agricultural Academy revealed fresh approach to recent problem - efficiency of physical education means during educational classes. It was proved that Pilates exercises had positive effect on state of health and physical fitness of students. It was demonstrated by increased indicators of lung capacity, which implies increase of functional level of training. Moreover, strength indicators also increased (turning up and lowering the body while lying on the back and pushing-up), as well as flexibility (toe touch bending while standing on a bench). During the experiment, students under test showed good results with respect to psychological state. The following indicators were improved - precision factor, endurance ratio, and development level of attention concentration. We suppose these to be important balance indicators of students psychoemotional state. In control group the indicators also increased, but insignificantly. Thus, the results of our research showed that Pilates is an effective means for developing physical qualities in PE classes.

\section{References}

1. M.S. Vorotova, L.V. Rubczova, I.M. Manurov, Physical Culture and Health, 3, 125-127, (2019)

2. R.S. Nagovitsyn, O.I. Vaganova, M.M. Kutepov, L.N. Martyanova, O.V. Kosenovich,Yu.V. Moeseev, M.S. Vorotova, A.Yu. Osipov, International Journal of Applied Exercise Physiology, 9(6), 77-84

3. A.S. Kuznetsov, Z.M. Kuznetsova, Russian Journal of Physical Education and Sport, 14(4), 5-7 (2019)

4. M.V., Zheleznyakova, N.Yu. Garbar, Pshycology and pedagogics: methodology and problems, 152-158

5. V.D. Ivanov, Z.I. Matina, Physical Culture. Sport. Tourism. Motor response, 3(1), 74-78 (2018)

6. E.V. Kaerova, L.V. Matveeva, Bulliten VGUE'S, 9(1), 168-180 (2017)

7. A.S. Kuznetsova, Z.M. Kuznetsova, Russian Journal of Physical Education and Sport, 14(4), 5-7 (2019)

8. O.Yu. Druzhinina, N.B. Vershinina, N.V. Zinkova, Methodology of development of strength quality of students at the training session of physical culture in agriculture: educational and methodical manual (Izhevsk State Agricultural Academy, Izhevsk, 2014) 